\title{
A NECESSIDADE SOCIAL DA NUTRIÇÃO ENQUANTO TEMA DA EDUCAÇÃO FÍSICA ESCOLAR
}

\author{
Guilherme Furuya Kuhn Grigollette, Lilian Christina Cruz Sanchez, José Ricardo Silva \\ Universidade Estadual Paulista - UNESP, Faculdade de Presidente Prudente, Presidente Prudente - SP. E-mail: \\ guilhermegrigollette@gmail.com
}

\section{RESUMO}

O objetivo deste texto é discutir sobre o papel do professor de educação física frente a saúde alimentar em âmbito escolar. Para tanto, utiliza-se como metodologia a pesquisa bibliográfica. Tomando como suporte teórico autores da abordagem saúde renovada, entendemos que a alimentação ou a falta dela decorre de diversos fatores, os quais destacamos: influência da mídia, consumo de alimentos industrializados e fast food, falta de conscientização e, por outro lado, a desnutrição decorrente do alto preço de alimentos considerados saudáveis. Esta diversidade de fenômenos desencadeiam diversos males à saúde. Por isso, apesar de sua atuação limitada, entendemos que a Educação Física escolar pode, a partir da abordagem da saúde renovada, desempenhar papel conscientizador das crianças acerca de hábitos alimentares saudáveis.

Palavras-chave: Educação Física Escolar; Problemas de saúde; Nutrição; Conscientização; Saúde.

\section{SOCIAL NECESSITY OF NUTRITION AS A SUBJECT OF SCHOOL PHYSICAL EDUCATION}

\begin{abstract}
The aim of this paper is to discuss the role of physical education teacher in front of the health food school setting. For both, is used as the methodology literature. Taking as authors theoretical support of renewed health approach, we understand the power or lack of it due to several factors, which include: media influence, consumption of processed foods and fast food, lack of awareness and, on the other hand, malnutrition due to the high price of food considered healthy. This diversity of phenomena trigger various health ailments. Therefore, despite its limited performance, we believe that Physical Education can, from the renewed health approach, role play conscientizing children about healthy eating habits.
\end{abstract}

Keywords: Physical Education; Health problems; Nutrition; Awareness; Health.

\section{INTRODUÇÃO}

Atualmente ao nos remetermos à nossa Educação Física escolar podemos, por meio de aparato teórico, identificar, analisar e criticar aquelas práticas que nos conduziram a uma identificação com a área e outras que não contribuíram para nossa formação. As práticas educacionais que se relacionavam com a Educação Física, por um lado, mostraram-se motivadora quando alguns professores conseguiam a partir de bases teóricas construir (re) significações e contextualizações capazes de romper co as práticas tradicionais do ensino nas aulas de Educação Física $^{1}$. 
Por outro lado, outros professores não tinham a mesma motivação para ensinar. Apenas disponibilizavam o material para a aula e ficavam sentados, à sombra, a espera do término da aula. Tais professores são conhecidos, pejorativamente, como 'professores bola' ou 'professores rola-bola', expressões que caracterizam práticas docentes reduzidas ao ato de distribuir os materiais didáticos aos alunos sem qualquer tipo de diretividade ${ }^{2}$.

Outro problema existente nas aulas de EF escolar é a discriminação. Existe por aqueles que não apresentavam desenvoltura nas aulas práticas, ou por estarem acima de seu peso ideal eram, estes deixados de lado. Conforme Costa, Souza e Oliveira ${ }^{3}$ estar acima do peso em uma sociedade que valoriza a aparência física e modelo de corpo ideal, faz do indivíduo alvo de discriminações, sobretudo em âmbito escolar.

Dentro desta complexidade, percebemos o quanto temas ligados ao desenvolvimento do corpo, tais como, a saúde, a má alimentação e o sedentarismo foram ausentes em nosso processo de formação na Educação Básica. E mais, vemos na mídia, redes sociais, no dia a dia com os familiares, parentes e amigos, crianças com taxas de triglicérides, colesterol elevado, obesidade, diabetes tipo 2, entre outros problemas. Relacionamos estes problemas, sobretudo, à falta de informação sobre saúde. Neste sentido, o objetivo deste artigo é discutir sobre o papel do professor de educação física frente à possíveis questões que se relacionam a saúde alimentar em âmbito escolar tomando como base orientadora, os autores da abordagem Saúde Renovada.

\section{METODOLOGIA}

Para atingir nosso objetivo, nos apoiamos na pesquisa bibliográfica, artigos científicos e livros da área. Para Ruiz ${ }^{4}$ este tipo de pesquisa tem por característica o levantamento e análise de material já produzido sobre o tema abordado.

\section{RESULTADOS}

Para iniciarmos nossas explanações, faz-se necessário definirmos alguns conceitos, tais como a fome e a vontade de comer. Angelis $^{5}$ diz que a fome é a necessidade de ingerir um alimento com urgência. Já o apetite é à vontade, o desejo de comer determinado alimento.

Se tratando de uma alimentação mais saudável é indispensável falarmos sobre a saúde. Palma, Estevão e Bagrichevsky ${ }^{6}$, dizem que a Organização Mundial de Saúde (OMS) expressa que a saúde é um bem estar físico, mental e social, ou seja, não é a ausência de doença ou enfermidade. Na nossa sociedade capitalista a desigualdade social é eminente, a distribuição de renda é feita de forma desigual, formada por uma sociedade na qual muitos têm pouco, e poucos têm muito, 
sendo impossível que a maioria tenha saúde, analisada pelo ponto de vista de um bem estar físico, mental e social.

Infelizmente há uma desigualdade social que inibe a maioria dos indivíduos a ter acessos à saúde. Segundo Mezzaroba ${ }^{7}$, a culpabilização da vítima, pelo aparecimento de doenças, e a prevenção não é uma responsabilidade pessoal, pois os indivíduos estão expostos às injustiças sociais que sofrem no dia a dia, por exemplo, más condições de alimentação, trabalho extenuante, transporte inadequado, entre outros.

Esta desigualdade gera prioridades distintas nas diferentes classes sociais, segundo Mezzaroba ${ }^{7}$, a classe média e alta tem acessos às práticas corporais das mais diversas, já a população na grande maioria pobre, não. A maioria dos indivíduos não tem como fazer uma alimentação saudável e nem a conscientização de como fazê-la. Segundo Palma, Estevão e Bagrichevsky ${ }^{6}$ e Mezzaroba ${ }^{7}$, a saúde é uma questão de multifatorial, pois engloba condições como: saneamento básico e esgoto, alimentação/nutrição, habitação, renda, meio ambiente, trabalho, transporte, emprego, lazer, práticas corporais, liberdade, acesso e posse de terra e acesso aos serviços de saúde.

\section{DISCUSSÃO}

Os hábitos alimentares inadequados contribuem para um crescente índice de obesidade infantil. É sabido que o sobrepeso traz danos à saúde, como hipertensão, diabetes, depressão, ansiedade, e baixa auto-estima ${ }^{8}$. Hinning e Bergamaschi ${ }^{9}$ chamam a atenção para o consumo de bebidas e doces industrializados em relação a diminuição do leite na alimentação dos escolares. Atualmente $^{10}, 80 \%$ das enfermidades serão decorrentes de distúrbios alimentares. Nossas crianças estão imersas em uma sociedade consumidora, realizam compras sozinhas, de modo especial nas escolas, tomando decisões alimentares de acordo com influências diversas ${ }^{11}$.

Para se promover a saúde faz-se necessário uma combinação entre ação educacional que incentivam comportamento e ações, a fim de levar à saúde. Executando metas e atividades para que todos os indivíduos tenham o mesmo comportamento. Neste caso, a promoção da saúde passa pela escola e transmite as melhores escolhas pessoais e responsabilidade e, um ambiente social adequado ${ }^{6}$. Neste sentido, fica claro que estes indivíduos não podem ser responsabilizados pelos seus problemas de saúde, já que questões de ordem sociais e políticos exercem papel determinante. E a desigualdade social, de um país em desenvolvimento, no qual a maioria da população é pobre, a alimentação acaba sendo para a maioria, apenas uma forma de sobrevivência, sem se preocupar com a nutrição dos alimentos. 
Deste modo, o papel da Educação Física frente às questões relacionadas a nutrição, alimentação saudável mesmo sendo limitado, deve se dizer a respeito às informações relacionadas a saúde como direito do cidadão, às práticas e comportamentos saudáveis ou não, à problematização e discussão acerca da temática, ao desenvolvimento de autonomia de pensamento, à reelaboração dos conhecimentos de modo a conformar valores, habilidades e práticas consideradas saudáveis ${ }^{6}$

A Educação Física escolar pode ajudar a promover a saúde, como forma de conscientização e informação sobre sua dimensão multifatorial, para que todos os alunos desenvolvam conhecimentos que os levem a escolhas mais saudáveis e a lutar por melhores condições de sua própria saúde e para seus pares.

Para Devide ${ }^{12}$ o professor de Educação Física deve estar atualizado ao conceito multifatorial relacionado à saúde, sua dimensão social, portanto, coletiva, para que, munido de instrumentação teórica consistente, tenha condições de discutir e ampliar sua relação com os alunos para além da esfera da aptidão física.

Não estamos advogando ao professor de Educação Física o papel de nutricionista escolar, no entanto, entendemos que este não deva se furtar do papel de mediador de informações que contribuam para que alunos que não possuam condições financeiras para buscar orientações com profissionais da área, possam, mesmo que incipientemente, tomar contatos com tais informações. O educador físico é um profissional genuinamente da saúde, com responsabilidades de associar fatores da atividade física, prevenção de doenças cardiovasculares e controle do estresse, aptidão física, saúde, alimentação saudável, conquistar adeptos ao estilo de vida ativo e, sobretudo, consciente, com o papel de reconhecer, querer e agir na busca pela integridade orgânica e psicossocial $^{13}$.

Para reforçar ainda mais esta ideia, Guedes e Nahas destacam a importância da Educação Física voltada para saúde. Para estes autores, ao fim da escolarização, os alunos deverão ser capazes de estabelecer relação entre todos os componentes da aptidão física e saúde, conhecer testes físicos, interpretar resultados e saber utilizá-los no planejamento autônomo de um programa de treino e avaliação pessoal. Para isso, o professor de Educação Física lançará mão de conhecimentos práticos e teóricos de atividade física, aptidão física e saúde, para o aluno entender os benefícios advindos da prática motora e utilizá-los por toda vida ${ }^{14}$. 


\section{CONCLUSÃO}

Os problemas nutricionais advêm de diversos fatores. Muitas crianças se alimentam mal, por falta de conhecimento, de conscientização dos pais, por falta de condições financeiras e pela manipulação da mídia pelos alimentos industrializados e fast food, alimentos esses que não tem valor nutricional recomendado pelos médicos e nutricionistas.

Tomando como base os autores aqui utilizados, estamos convencidos de que o profissional de Educação Física quando em âmbito escolar, pode desenvolver esta temática com o intuito de informar seus alunos sobre a importância, a necessidade e ajudá-los a compreender as diversas razões que levam algumas pessoas a não desenvolverem hábitos alimentares saudáveis. Para isso, o professor de EF deve conhecer a realidade de seus alunos, e conscientizá-lo sobre as questões de problemas de saúde decorrente de maus hábitos alimentares, nutrição, a importância da alimentação adequada para vida humana, como forma de prevenção de diversas doenças, dentro das possibilidades dos mesmos. Com isso, muitos alunos poderão ser atingidos, beneficiando a si próprios e até mesmo suas famílias.

\section{REFERÊNCIAS}

1. Faria, B. A.; Bracht, V.; Machado, T. S.; Moraes, C. E. A.; Almeida, U. R.; Almeida, F. Q. Inovação pedagógica na educação física. $\mathrm{O}$ que aprender com as práticas bem sucedidas? Àgora para la ef deporte. v. 12, 2010, p. 11-28.

2. Machado, T. da S.; Bracht, V.; Faria, B. A.; Moraes, C.; Almeida, U.; Almeida, F. Q. As práticas de desinvestimento pedagógico na Educação Física escolar. Movimento, Porto Alegre. v. 16, n. 02, abril - junho de 2010, p. 129 - 147.

3. Costa, M. A. P. da; Souza M. A.; Oliveira, V. M. de. Obesidade infantil e bullying: a ótica dos professores. Educ.Pesqui. vol.38 no 3. São Paulo jul/set 2012, p. 655.

http://dx.doi.org/10.1590/S1517-97022012005000017

4. Ruiz, J. A. Metodologia Científica: guia para a eficiência nos estudos. São Paulo, Atlas, 1996.

5. Angelis, R. C. de. Fome Oculta, bases fisiológicas para reduzir seus riscos através de alimentação saudável. Editora Atheneu. São Paulo, 2000.

6. Palma, A.; Estevão, A; Bagrichevsky, M. Considerações teóricas acerca das questões relacionadas à promoção da saúde. (In) Bagrichevsky, M.; Palma, A.; Estevão, A. (orgs). A saúde em debate na educação física. Editora Edibes. Blumenau, 2003.

7. Mezzaroba, C. Ampliando o olhar sobre saúde na educação física escolar: críticas e possibilidades no diálogo com o tema do meio-ambiente a partir da saúde coletiva. Motrivivência. Ano XXIX, n 38, 2012, p. 232-246. 
8. Parkpour, A. H; Yeakaninejad, M. S. A percepção das mães sobre a obesidade em escolares. Uma pesquisa e o impacto de uma intervenção educativa. J.Pediatr. (Rio J.) vol.87 no.2 Porto Alegre Mar/Apr. 2011, p. 170.

9. Hinning, P. de F.; Bergamaschi, D. P. Itens alimentares no consumo alimentar de crianças de 7 a 10 anos. Rev. Bras. epidemiol. vol. 15 no. 2. São Paulo. June. 2012, p. 331.

http://dx.doi.org/10.1590/S1415-790X2012000200010

10. Simões, A. L. A.; Stacciarin, T. S. G.; Poggetto, M. T. D.; Maruxo, H. B.; Soares, H. M.; Simões, A. C. de A. Conhecimento dos professores sobre manejo da criança com diabetes mellitus. Texto contexto-enferm.vol.19 no.4 Florianópolis. Oct./Dec. 2010, p. 652.

http://dx.doi.org/10.1590/S0104-07072010000400007

11. Veiga Neto, A. R.; Nogueira, L. G.; Melo, S. de. Fatores de influências no comportamento de compra de alimentos por crianças. Saúde soc. Vol. 22 no. 2. São Paulo. Apr./June 2013, p. 443.

12. Devide. F. P. A educação física escolar como via de educação para a saúde. (In) BAGRICHEVSKY, M; PALMA, A.; ESTEVÃO, A. (orgs). A saúde em debate na educação física. Editora Edibes.

Blumenau, 2003, p. 331.

13. Barbosa R. M. S. P. Resenha do livro "Atividade Física, Saúde e Qualidade de Vida: conceitos e sugestões para um estilo de vida ativo", de Markus Vinicius Nahas. Rev. Bras. Ciênc. Esporte vol.34 no.2 Porto Alegre Apr./June 2012, p. 514. http://dx.doi.org/10.1590/S010132892012000200018

14. Fernandes, A. As abordagens pedagógicas renovadoras na educação física escolar e a autonomia: algumas reflexões. Revista LOGOS, n. 16, 2008, p. 3-13. 